\title{
Severe Immune Presence
}

National Cancer Institute

\section{Source}

National Cancer Institute. Severe Immune Presence. NCI Thesaurus. Code C159475.

Greater than 50 percent of the tissue surface area is occupied by immune cell infiltration. 